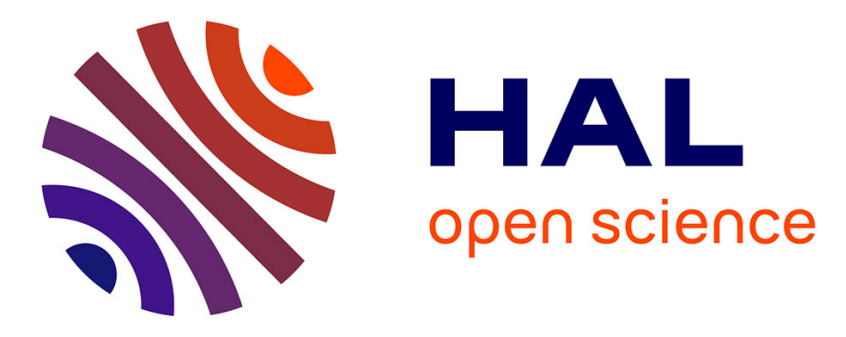

\title{
Sustainable Peatland Management with IoT and Data Analytics
}

Jiun Terng Liew, Aduwati Sali, Nor Kamariah Noordin, Borhanuddin Mohd. Ali, Fazirulhisyam Hashim, Syamsiah Mashohor, Nur Luqman Saleh, Yacine Ouzrout, Aicha Sekhari

\section{To cite this version:}

Jiun Terng Liew, Aduwati Sali, Nor Kamariah Noordin, Borhanuddin Mohd. Ali, Fazirulhisyam Hashim, et al.. Sustainable Peatland Management with IoT and Data Analytics. 22nd Working Conference on Virtual Enterprises (PRO-VE 2021), Nov 2021, Saint-Etienne, France. pp.549-557, 10.1007/978-3-030-85969-5_51. emse-03346490

\section{HAL Id: emse-03346490 https://hal-emse.ccsd.cnrs.fr/emse-03346490}

Submitted on 25 Nov 2021

HAL is a multi-disciplinary open access archive for the deposit and dissemination of scientific research documents, whether they are published or not. The documents may come from teaching and research institutions in France or abroad, or from public or private research centers.
L'archive ouverte pluridisciplinaire HAL, est destinée au dépôt et à la diffusion de documents scientifiques de niveau recherche, publiés ou non, émanant des établissements d'enseignement et de recherche français ou étrangers, des laboratoires publics ou privés. 
Liew J.T. et al. (2021) Sustainable Peatland Management with IoT and Data Analytics. In: Camarinha-Matos L.M., Boucher X., Afsarmanesh H. (eds) Smart and Sustainable Collaborative Networks 4.0. PRO-VE 2021. IFIP Advances in Information and Communication Technology, vol 629. Springer, Cham. https://doi.org/10.1007/978-3030-85969-5_51

\title{
Sustainable Peatland Management with IoT and Data Analytics
}

\author{
Jiun Terng Liew ${ }^{1}$, Aduwati Sali ${ }^{1}$, Nor Kamariah Noordin ${ }^{1}$, Borhanuddin Mohd. \\ Ali $^{1}$, Fazirulhisyam Hashim ${ }^{1}$, Syamsiah Mashohor ${ }^{1}$, Nur Luqman Saleh ${ }^{1}$, \\ Yacine Ouzrout ${ }^{2}$ and Aicha Sekhari ${ }^{2}$ \\ ${ }^{1}$ Wireless and Photonic Networks Research Centre of Excellence (WiPNET), Faculty of \\ Engineering, UPM, Malaysia \\ ${ }^{2}$ Université Lumière Lyon 2, 86 Rue Pasteur, \\ 69007 Lyon, France \\ \{liewjt, aduwati, nknordin, borhan, \\ fazirul, syamsiah, nurluqmansaleh\}@upm.edu.my \\ \{yacine.ouzrout, aicha.sekhari\}@univ-lyon2.fr
}

\begin{abstract}
Peatland is important to rural communities' livelihood due to its potential for aquaculture and agriculture. Nonetheless, human activities such as slash-and-burn can greatly increase forest fire risk, which can release a great amount of greenhouse gases and carbon dioxide into the atmosphere. To sustainably manage and restore peatlands, the Internet of Things (IoT) system can incorporate with Cyber-Physical System (CPS) for peatland management. In this study, an IoT system is deployed in the peatland to monitor the ground water level (GWL) and upload it to the server for the machine learning (ML) process. The trend of GWL will be modelled, and the CPS using the developed ML model will control the peatland rewatering process. As a result, the peatland condition can be monitored in real-time, and the risk of forest fire can be mitigated through rewatering automation before the GWL drops to a critical level.
\end{abstract}

Keywords: Machine learning, peatland, sustainable, IoT, CPS.

\section{Introduction}

\subsection{Backgrounds}

Peatland is the accumulation of partially decayed organic materials due to the waterlogged soils causing the anaerobic condition, where the rate of organic matter production exceeds the decomposition rate [1]. As a result, the peatland is a gigantic pool of carbon storage and habitat for many natural wildlife [2]. Peatland is also very important for water management as it can hold water equivalent to 20 times its own weight. Tropical peatland is commonly found in South-East Asia region, covering around 23.6 million hectares which represents 56 per cent of the global tropical peatland. 
For rural communities, peatland is the key to their livelihood due to its potential of aquaculture, agriculture, collection and utilization of forest products. As a result, deforestation rate of peatland reached almost 4 percent per annum, which is comparatively higher than other forest type [3]. Timber extraction using drainage method often damage the forest with poor recovery and depleted conditions [4]. Furthermore, large scale agriculture development for rice plantation involving slashand-burn has driven the peat swamp forest loss and leaves the areas susceptible to annual forest fires.

Overall, overexploitation has severely harmed the peatland and increased the risk of forest fire. To make the matter worst, peatlands are the most critical terrestrial carbon sink of the world. The carbon is stored mainly in the peat form and peatlands plays an important role in regulation of climate by absorbing great amounts of carbon dioxide $\left(\mathrm{CO}_{2}\right)$. Forest fires in peatland not only release the $\mathrm{CO}_{2}$ into the atmosphere, but also two other greenhouse gases, namely methane $\left(\mathrm{CH}_{4}\right)$ and nitrous oxide $\left(\mathrm{N}_{2} \mathrm{O}\right)$. Therefore, effective method of peatland forest fires management is key to sustainable environment and climate change mitigation.

In this work, a collaborative Internet of Things (IoT) and Cyber-physical System (CPS) system is proposed for sustainable peatland management. IoT system is deployed in the peatland to collect real-time in-situ data to replace the conventional data collection method involving labor-intensive measurement by professional. Data collected by the IoT system is uploaded to the server for data analytic process. The data analytic process helps to predict the trend of Ground Water Level (GWL), which is key to determine the risk of forest risk. Based on the risk projected, CPS conduct the hydrological management using automated water pump facilities. Consequently, the GWL of peatland can be sustainably managed and preventing the occurrence of peatland forest fire.

\section{$1.2 \quad$ Related Works}

Hydrological management is a proven-effective method in ensuring the peatland ecosystem sustainability and preventing natural fires. During dry season, forest fire is more likely to happen if the GWL of the area is low. Hence, to maintain a high GWL - reduced risk of major fire, blocking of drainage ditches in peatland forest can be conducted. While fires caused by slash-and-burn cannot be exterminated through water management, high GWL can mitigate the spreading of forest fires. For high fire risk areas, rewatering process can be employed by pumping water from nearby rivers and lakes, to ensure the GWL is not more than $20 \mathrm{~cm}$ below the surface [5].

Wireless Sensor Network (WSN) or the more advanced IoT network have demonstrated both their flexibility and capability in handling various applications such as fleet management, localization, and healthcare $[6,7,8]$. Similarly, CPS has displayed great potential in industrial automation, where a feedback loop is created and integrated with decision making and appropriate response from actuators [9]. In [10], Intelligent predictive management (IPdM) is proposed to achieve zero-defect manufacturing (ZDM) through data-driven CPS. Similarly, [10] explored the architecture of dynamic manufacturing IoT with real-time data collection. Overall, CPS and IoT has shown promising traits that can be used to help manage the peatland. 
Due to the ongoing threat of transboundary haze caused by peatland forest fire, peatland management has received a lot of attention in South-East Asia. In [11], an IoT system with piezometers known as AGROMIST is deployed to collect the peatland data in real-time and help improve the water management. Authors of [12] take on a similar approach and improve system by including local atmospheric data into the analysis. To encourage the involvement of stakeholders in the effort of peatland management, [13] used a LoRa-based IoT network to collect the ground parameters and upload to dashboard that is easily accessible.

To fully harness the potential of IoT along with CPS, the author proposed to incorporate IoT with CPS for the peatland management. In this work, an IoT network using LoRa technology is deployed on site to monitor the condition of the peatland, including ground data and atmospheric data. Collected data are uploaded to the server and undergone data analytic process for GWL prediction. Based on the outcome of data analytic, the CPS consists of peatland water pump room will be controlled to automate the peatland rewatering process. Rewatering process commenced is based on the forest fire risk code detailed by the Global Environment Centre to minimize the chance of fire occurrence.

\section{Methodology}

In this section, the architecture and working principle of proposed peatland management system is discussed.

\subsection{IoT System with CPS}

To aid the peatland management, the condition of peatland must be monitored constantly. As such, an IoT system consist of ground sensor nodes (i.e., piezometer), in-situ weather station and LoRa gateway is deployed. The overall architecture of the IoT system is shown in Fig.1. LoRa communication technology is used for the local sensor nodes' communication due to its low power and low connectivity cost [14]. A reliability test was conducted using the LoRa scanner to verify the packet delivery rate of the network. Subsequently, the spreading factor and data rate of the network are configured for the best performance. At the center of the map, there is an observation tower with the height of approximately 25 meters above ground. Weather station and LoRa gateway are installed near the top of the tower to avoid signal distortion by the peatland bushes and trees (around 2 to 10 meters of height and of various density). LoRa gateway will aggregate all the data collected by the local sensor node, and upload to the cloud server using $4 \mathrm{G}$ cellular communication. The cloud server is located at MIMOS Malaysia, which is also responsible for the development of dashboard for collected data. The dashboard is accessible for local stakeholders for peatland monitoring and promote more efficient management process. Weather station installed is used to collect all the in-situ atmospheric data, including all the Fire Danger Rating System (FDRS) parameters (i.e., wind speed, ambient temperature, relative humidity, accumulated precipitation). Both the weather 
station and LoRa gateway are solar powered using the solar panel installed on top of the observation tower.

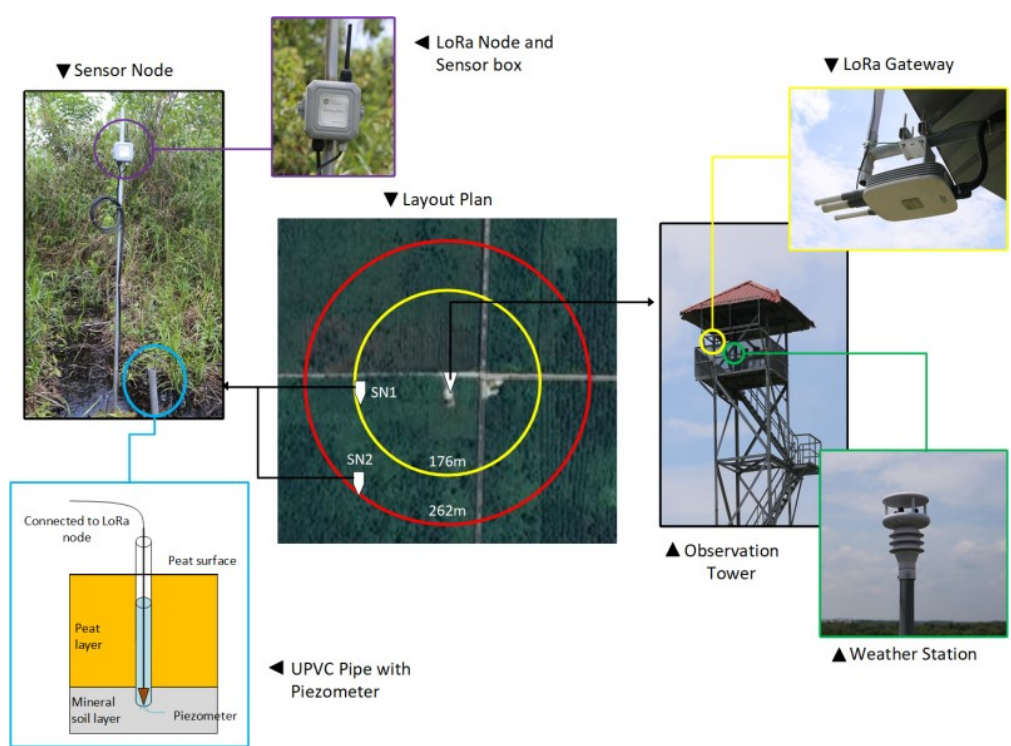

Fig. 1. Overall layout plan of the deployed IoT system, with each component highlighted.

Two ground sensor nodes are installed at forest fire prone area suggested by the forest rangers from Selangor State Forestry Department. Ground data, including soil temperature and GWL or water table are monitored by the sensor nodes. These sensor nodes are battery powered and the battery status along with the Signal to Noise Ratio (SINR) and collected ground data are transmitted to the LoRa gateway. The location of sensor node 1 (SN1) and sensor node 2 (SN2) are depicted in the Fig. 1.

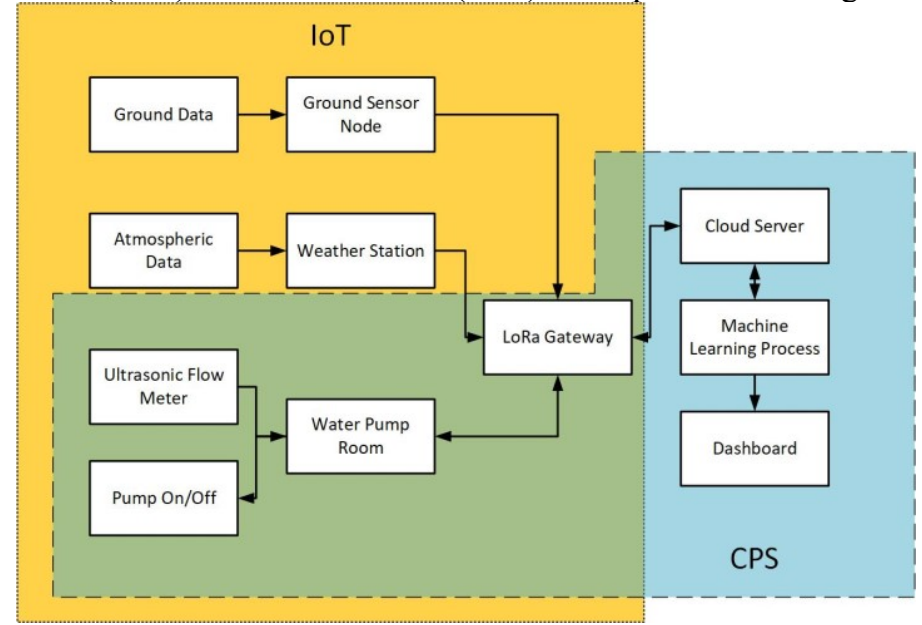

Fig. 2. Block diagram of IoT and CPS. 
For the CPS, the plan is to integrate the water pump room into the IoT system for automated rewatering process. The block diagram of the collaborative IoT and CPS is illustrated in Fig. 2. The direction of the arrow represents the transmission direction of the data. 1-way arrow means the data is transmitted from source to the destination, whilst 2-way arrow means both uplink and downlink process are involved. Water is pumped from the nearby reservoir and distributed to the peatland using systematically installed water pipes. The water pump room is shown in the Fig. 3, where ultrasonic flow sensor is used to monitor the amount of water pumped to the peatland. The water pump room is also powered by solar panel for sustainable power management. Through the combination of cloud-based data analytic, the CPS can collaborate with the IoT system for automated actuating process and open up the possibility to smarter decision-making using external data.

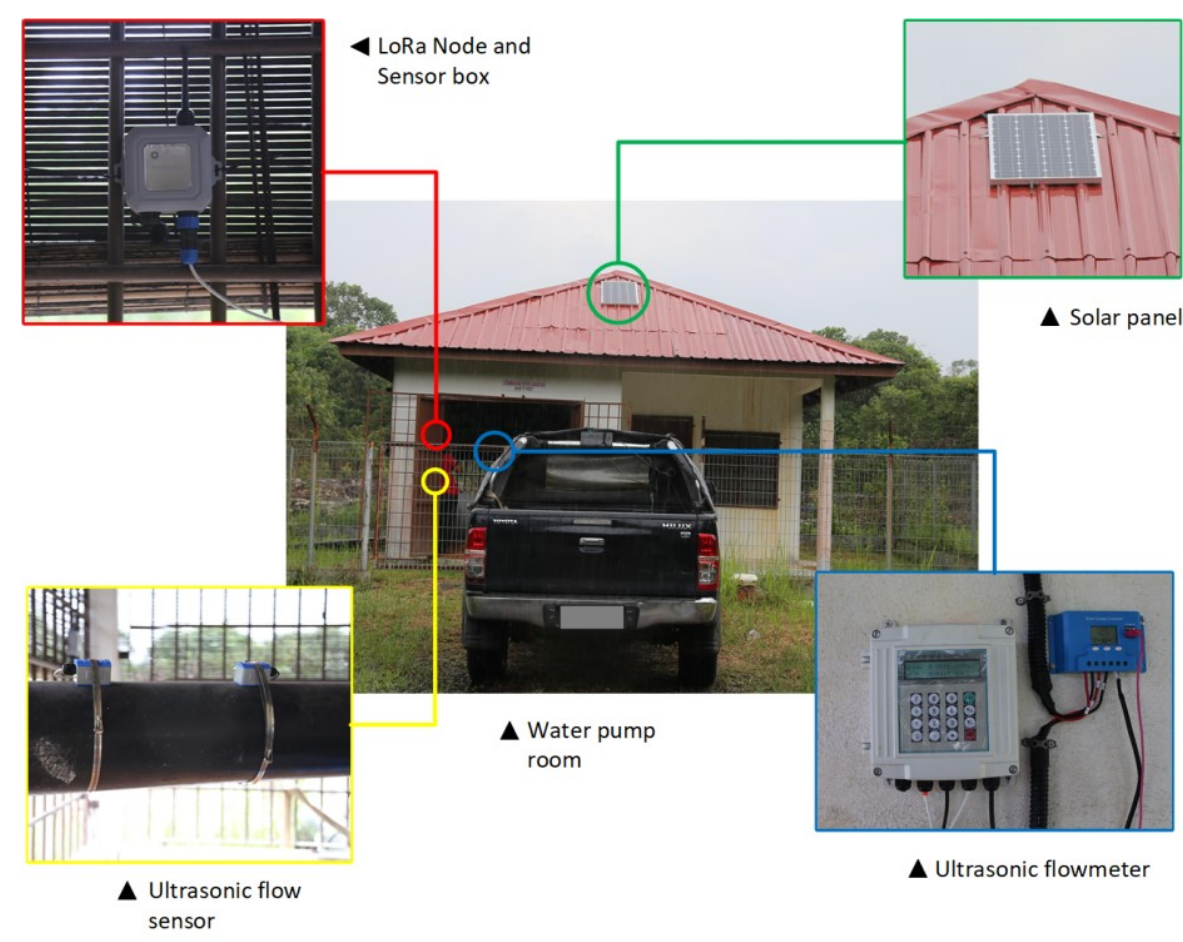

Fig. 3. Water pump room and its components.

\subsection{Data Analytics}

Efficient peatland management, especially rewatering method is a time-consuming process. It is benefited to commence the rewatering process early before the GWL drops to a critical level. Therefore, a GWL prediction model is developed using machine learning (ML). The complete process of the ML is depicted in Fig. 4. Prior to the training of ML model, the input data are cleaned and pre-processed. Multivariate 
regression is used because it encompasses the simultaneous analysis of more than one dependent variable (next-hour SN1 and SN2 GWL, next-day SN1 and SN2 GWL) based on more than one independent variable (FDRS parameters)

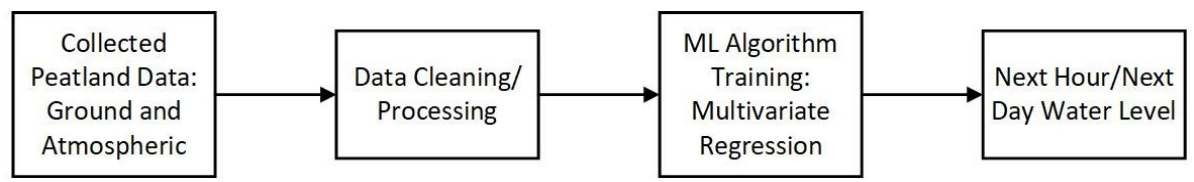

Fig. 4. Complete procedure of ML in proposed peatland management.

In this ML model, FDRS parameters and GWL detected by SN1 and SN2 are used as training attributes. The label of the ML model will be next hour and next day GWL. Alert system and automated of the water pump room will be based on the projected GWL comparing to the fire risk code. The main objective is to maintain the peatland GWL sustainably and stably at low fire risk according to the fire risk table provided by Global Environment Centre (GEC), tabulated in Table 1. To avoid disruption to the establishing vegetation, the water level will halt after the low fire risk is achieved, i.e., GWL around $0 \mathrm{~mm}$.

Table 1. Fire Risk Codes from GEC

\begin{tabular}{|c|c|c|}
\hline $\begin{array}{l}\text { Water Table } \\
\text { Range (mm) }\end{array}$ & Depth Colour Code & Fire Risk \\
\hline 500 to 0 & Blue & Low \\
\hline-500 to 0 & Green & Medium \\
\hline-500 to -700 & Yellow & High \\
\hline-700 to -1000 & Red & Extreme \\
\hline
\end{tabular}

\section{Results and Discussion}

For ML training, the data collected between January 2020 until March 2020 is used for the proof of concept. These data are verified, cleaned and subject to preprocessing, including standard scaler and attribute selection. After the cleaning process, 1739 data points are available in total. Following the data splitting, 1391 and 348 data points are used as train set and test set, respectively. GWL is the focus of this study as the CPS involves peatland rewatering process to reduce the risk of peatland forest fire. Fig. 5 shows the trend of the GWL over the course of 3 months. The distance of the deployed ground sensor nodes is estimated around $86 \mathrm{~m}$, so the recorded GWL is expected to demonstrate similar trend. From the figure, the trend of the GWL recorded is almost identical, with a Pearson Correlation of 0.9695 . The difference of the water level is constantly maintained at approximately $200 \mathrm{~mm}$. 

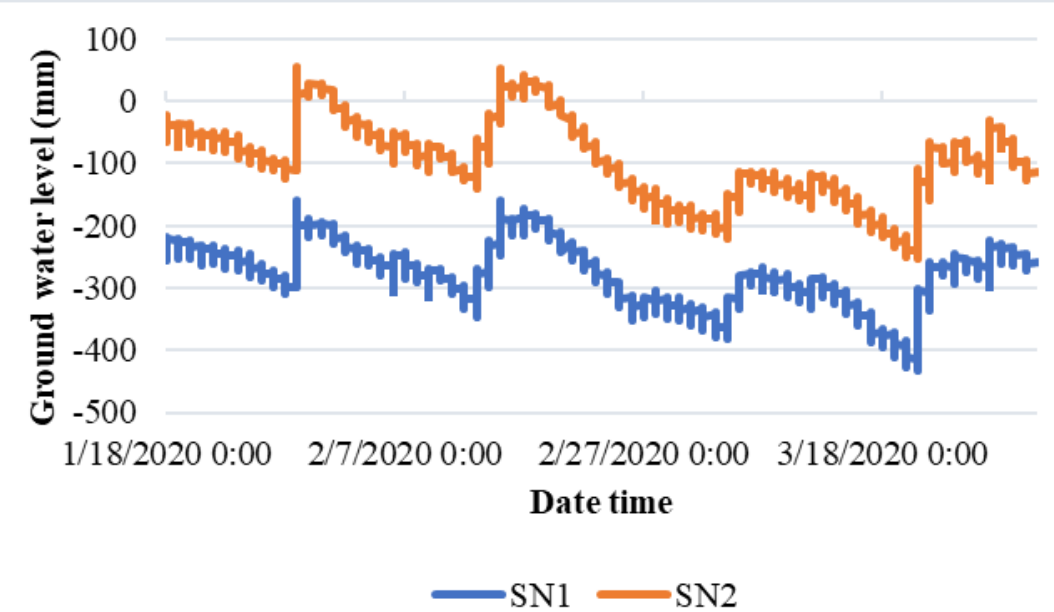

Fig. 5. GWL recorded by ground sensor nodes.

Fig. 6 illustrated the performance of our ML model in predicting the next hour water level in mm after comparing the predicted values with true values. Blue line plotted on the graph represent the perfect prediction, while the red dots are predicted water level against the true water level. It is obvious that the trained ML model has very good level of performance in terms of predicting the GWL for both SN1 and SN2. Upon analysis, the root mean square errors (RMSEs) of the ML model for next hour water level prediction are 7.2221 and 7.6592 for SN1 and SN2, respectively.
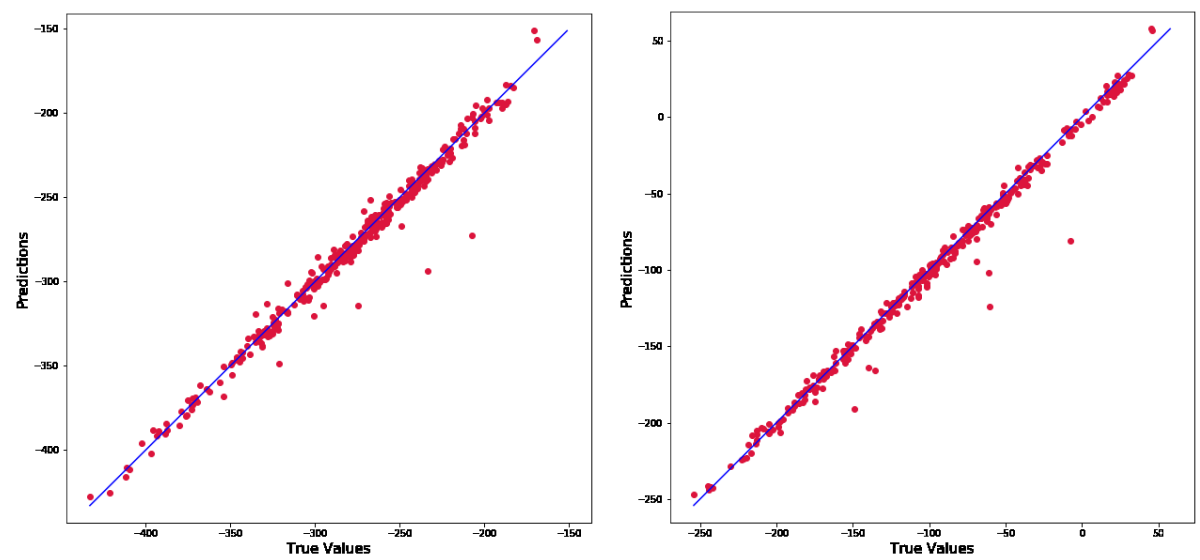

Fig. 6. Performance of ML model in predicting next hour GWL, left for SN1, right for SN2.

The ML model for next day water level prediction is also developed as a safety measure in case of any unexpected problem occurred to the water pump room or rewatering process. The performance of the ML model is shown in Fig. 7. Compare the performance of next hour prediction, the performance of ML model in predicting 
next day GWL has slightly degraded. This observation is reasonable as the relevancy of data at current time degrades heavily over the span of 24 hours. Nonetheless, the projected values (red dots) still lie very close to the true values (blue line). The RMSEs of the ML model are 25.1012 and 29.8331 for SN1 and SN2, respectively. According to the 68-95-99 rule [15], this means that 99.7 per cent of the prediction by the developed ML model will fall within the $75.303 \mathrm{~mm}$ and $89.499 \mathrm{~mm}$ of the actual GWL for SN1 and SN2, respectively
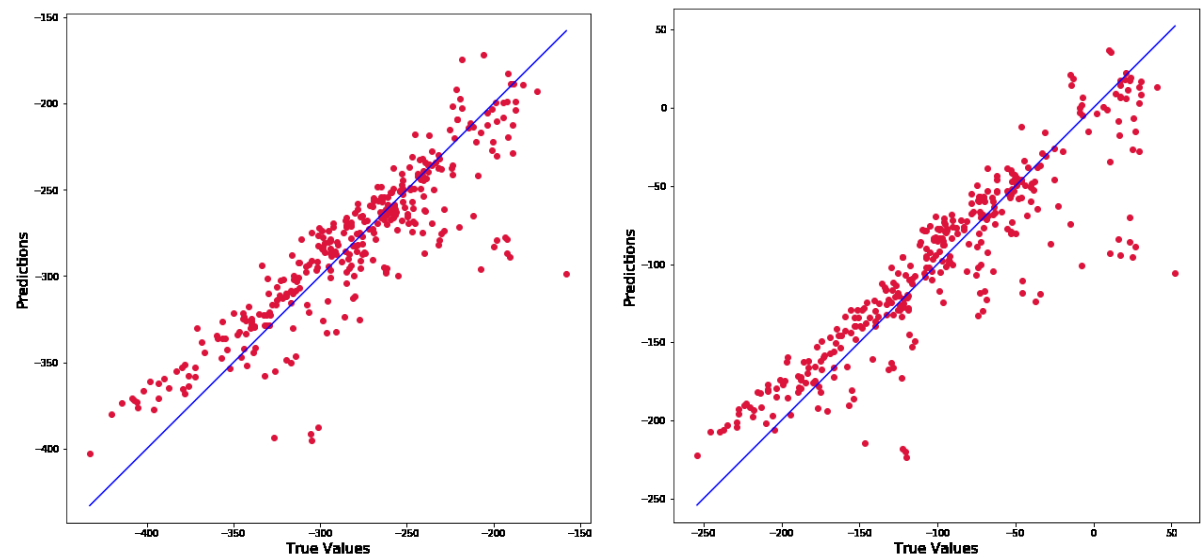

Fig. 7. Performance of ML model in predicting next day GWL, left for SN1, right for SN2.

\section{Conclusion}

In this study, a IoT system with CPS is proposed for sustainable peatland management. The reliability of IoT system to collect real-time data from the peatland can effectively reduce the labour cost of peatland management. Wireless communication at the site is established using LoRa technology for cost efficient transmission. Collected data are aggregated at the in-situ LoRa gateway before uploaded to the cloud server for dashboard presentation and data analytic process. ML model is developed using the collected data to predict the ground water level of the peatland in one hour and 24 hours. The RMSEs of the developed ML model are averaged at 7.4407 and 27.4672 for next hour and next day ground water level prediction, respectively. The ability to estimate the peatland ground water level enable the stakeholder to take early initiatives in reducing the occurrence of forest fire. Water pump room at the peatland is integrated as part of the CPS to automate the water distribution process from the nearby reservoir.

For future work, the ML model will be trained with more data, including data collected from Meteorological Department Malaysia. Apart from the prediction of GWL, the dashboard of the system will be furnished with calculation of real-time Fire Weather Index. Furthermore, discussion has been held with the regulatory bodies to enhance the system with surveillance system for prevention of illegal slash-and burn activities. 
Acknowledgments. The authors would like to acknowledge NICT Japan and ASEAN-IVO for funding this project NAPC (Networked ASEAN Peatland Forests Communities), Selangor State Forestry Department (JPNS) for permission to deploy the IoT system, MetMalaysia, LORANET Technologies and Global Environment Centre (GEC) for valuable feedback and validation of peatland data.

\section{References}

1. Craft, C.: Creating and restoring wetlands: From theory to practice. Elsevier (2015)

2. Harenda, K. M., Lamentowicz, M., Samson, M., Chojnicki, B. H.: The role of peatlands and their carbon storage function in the context of climate change. In Interdisciplinary approaches for sustainable development goals, pp. 169-187, Springer (2018)

3. Lo, J., Parish, F.: Peatlands and Climate Change in Southeast Asia. ASEAN Secretariat and Global Environment Centre (2013)

4. Istomo, K.E., Tata, H.L., Sumbayak, E.S., Rahma, A.: Evaluation of Silviculture Systems in Peat Swamp Forest in Indonesia. In: Pusat Penelitian dan Pengembangan Hutan dan Konservasi Alam bekerjasama dengan. ITTO CITES Project. Indonesia (2010).

5. Natural Environment Agency: Asean Guidelines on Peatland Forest Fire Management. (2015)

6. Zantalis, F., Koulouras, G., Karabetsos, S., Kandris, D.: A Review of Machine Learning and Iot in Smart Transportation. Future Internet 11, 4, 94 (2019)

7. Paul, A.K., Sato, T.: Localization in Wireless Sensor Networks: A survey on Algorithms, Measurement Techniques, Applications and Challenges. Journal of Sensor and Actuator Networks 6, 4, 24 (2017).

8. Dey, N., Ashour, A.S., Shi, F., Fong, S.J., Sherratt, R.S.: Developing Residential Wireless Sensor Networks for ECG Healthcare Monitoring. IEEE Transactions on Consumer Electronics 63, 4, 442-449 (2017).

9. Baudouin, D., Moalla, N., Ouzrout, Y.: The Challenges, Approaches, and Used Techniques of CPS for Manufacturing in Industry 4.0: A Literature Review. The International Journal of Advanced Manufacturing Technology, 1-18 (2021)

10. Cheng, L., Wang, T., Hong, X., Wang, Z., Wang, J., Liu, J.: A Study on the Architecture of Manufacturing Internet of Things. International Journal of Modelling, Identification and Control 23, 1, pp.8-23 (2015)

11. Ismail, M.E.R., Shukri, I.F.A., Azmi, A., Yahya, Y., Ismail, S.A., Sulaiman, M.S.: Development of Agronomist Station System for Water Table Management at Peatland. In: 2019 6th International Conference on Research and Innovation in Information Systems (ICRIIS). IEEE, pp. 1-6 (2019)

12. Sali, A., Ali, A.M., Ali, B.M., Rahman, S.M.S.A.A., Liew, J.T., Saleh, N.L., Nuruddin, A.A., Razali, S.M., Nsaif, I.G., Ramli, N., Mohammad, H.: Peatlands Monitoring in Malaysia with IoT Systems: Preliminary Experimental Results. In: International Conference on Computational Intelligence in Information System, pp. 233-242. Springer (2021)

13. Essa, S., Petra, R., Uddin, M.R., Suhaili, W.S.H., Ilmi, N.I.: IoT-based Environmental Monitoring System for Brunei Peat Swamp Forest. In: 2020 International Conference on Computer Science and Its Application in Agriculture (ICOSICA), pp. 1-5. IEEE (2020)

14. Petäjäjärvi, J., Mikhaylov, K., Pettissalo, M., Janhunen, J., Iinatti, J.: Performance of a Low-power Wide-area Network based on LoRa Technology: Doppler Robustness, Scalability, and Coverage. International Journal of Distributed Sensor Networks, 13, 3. (2017) 
15. Warren, R. M.: Visual intensity judgments: An empirical rule and a theory. Psychological Review, 76, 6, (1969). 